\title{
Cloning and Expression Analysis of a Gene Encoding for Ascorbate Peroxidase and Responsive to Salt Stress in Beet (Beta vulgaris)
}

\author{
Kamila Dunajska-Ordak • Monika Skorupa-Kłaput • \\ Katarzyna Kurnik • Andrzej Tretyn • Jarosław Tyburski \\ Published online: 18 August 2013 \\ (C) The Author(s) 2013. This article is published with open access at Springerlink.com
}

\begin{abstract}
B v \mathrm{pAPX}$ is a full-length cDNA-encoding peroxisomal ascorbate peroxidase isolated from leaves of saltstressed beet (Beta vulgaris) plants. A high level of identity has been reported between the deduced amino acid sequence of $B v \mathrm{pAPX}$ and other known ascorbate peroxidases. The genomic sequence of $B v \mathrm{pAPX}$ revealed a gene composed of 5 exons and 4 introns. Several sequence motifs revealed in the 5'UTR region of the gene confer to $B v \mathrm{pAPX}$ a putative responsiveness to various abiotic stresses. We determined the effect of salt stress on BvpAPX expression in leaves of the cultivated beet varieties, Huzar and Janosik, and their wild salt-tolerant relative $B$. vulgaris ssp. maritima. Plants were subjected to salt stress during a 32-day culture period (long-term salt treatment). An alternative salinization protocol consisted of an 18-h incubation of detached beet leaves in media supplemented with toxic salt concentrations (short-term salt treatment). RT-Q-PCR analysis revealed that $B v \mathrm{pAPX}$ expression markedly increased in leaves of plants subjected to conditions of long-term treatment with salinity, whereas $B v$ pAPX transcript levels remained unaffected in detached leaves during short-term salt treatment. In addition, several leaf redox system parameters, such as ascorbate peroxidase activity or ascorbic acid, hydrogen peroxide, and lipid
\end{abstract}

K. Dunajska-Ordak and J. Tyburski contributed equally to this work.

Electronic supplementary material The online version of this article (doi:10.1007/s11105-013-0636-6) contains supplementary material, which is available to authorized users.

K. Dunajska-Ordak · M. Skorupa-Kłaput $\cdot$ K. Kurnik · A. Tretyn • J. Tyburski $(\square)$

Chair of Plant Physiology and Biotechnology, Nicolas Copernicus

University, Lwowska 1, 87-100 Toruń, Poland

e-mail: tybr@umk.pl

A. Tretyn · J. Tyburski

Centre for Modern Interdisciplinary Technologies, Nicolas

Copernicus University, Wileńska 4, 87-100 Toruń, Poland hydroperoxide concentration, were determined in the leaves of beet plants subjected to salt stress conditions.

Keywords Ascorbate $\cdot$ Ascorbate peroxidase $\cdot$ Beta vulgaris $\cdot$ Hydrogen peroxide $\cdot$ Salt stress

\section{Introduction}

It is widely known that the negative effect of environmental stresses is largely due to oxidative damage provoked by reactive oxygen species (ROS). Highly reactive products of the partial reduction of molecular oxygen $\left(\mathrm{O}_{2}\right)$, such as superoxide radical $\left(\mathrm{O}_{2}{ }^{-}\right)$, hydrogen peroxide $\left(\mathrm{H}_{2} \mathrm{O}_{2}\right)$, or hydroxyl radical $\left(\mathrm{OH}^{-}\right)$, are commonly classified as ROS, which also include singlet oxygen and fatty acid radicals (Bhattacharjee 2005; Foyer and Noctor 2005; Shao et al. 2008).

Cellular ROS levels are controlled by an interrelated network of low-molecular mass antioxidants and ROSscavenging enzymes. Antioxidative systems modulate ROS homeostasis by regulating levels of $\mathrm{O}_{2}^{-}$and $\mathrm{H}_{2} \mathrm{O}_{2}$. In plant cells, the ascorbate-glutathione (ASC-GSH) cycle, which is a highly coordinated chain of biochemical reactions, plays a vital role in adjusting $\mathrm{H}_{2} \mathrm{O}_{2}$. Reduction of $\mathrm{H}_{2} \mathrm{O}_{2}$ to $\mathrm{H}_{2} \mathrm{O}$ by ascorbate peroxidase (APX) at the expense of two ascorbate molecules (ASC) is the crucial step in this sequence of redox reactions. While providing the reducing power for $\mathrm{H}_{2} \mathrm{O}_{2}$ reduction, ASC is oxidized to monodehydroascorbate (MDHA), an unstable, non-reactive free radical. MDHA undergoes a spontaneous disproportionation providing equimolar amounts of ASC and dehydroascorbate (DHA), a fully oxidized form of ascorbate. ASC may be recycled either directly from MDHA by MDHA reductase (MDHAR) or from DHA in a reaction catalyzed by DHA reductase (DHAR). The electrons for MDHA and DHA reduction are provided by NADPH and glutathione (GSH), respectively. ASC-GSH cycle enzymes are present in the cytosol, 
chloroplast, and peroxisome (Dąbrowska et al. 2007; Ishikawa and Shigeoka 2008).

Due to its activity in various compartments of plant cells, APX plays a key role in regulating $\mathrm{H}_{2} \mathrm{O}_{2}$ homeostasis and adjusting redox metabolism to changing environmental conditions. APX activity directly affects the ASC/DHA redox state and indirectly through the enzymatic machinery of the ASCGSH cycle, the redox homeostasis of the glutathione pool. Provided that $\mathrm{H}_{2} \mathrm{O}_{2}$ is a key oxidant and ASC/DHA and GSH/GSSG redox pairs are both crucial cellular redox buffers and redox sensors, APX seems to have an important role in both the regulation of the redox environment of plant cells and induction of the tolerance mechanisms to environmental stresses (Davletova et al. 2005; Dąbrowska et al. 2007; Ashraf 2009).

APX is present in all higher plants and ASC-synthesizing algae. Alongside cytochrome c peroxidase and catalaseperoxidase from cyanobacteria, APX is classified as a member of the class I peroxidase family. Genes encoding APX isoenzymes are a multigene family composed of 9 genes in Arabidopsis thaliana, 8 in rice, and 7 in tomato. The APX family is further subdivided according to the cellular localization of the proteins in the chloroplast, cytosol, and peroxisome. Chloroplast APX is found as thylakoid-bound (tAPX) or soluble stromal (sAPX) forms. The amino acid sequence of tAPX is characterized by a hydrophobic domain that enables the protein to dock in the thylakoid membrane. A separate gene for mitochondrial APX has not yet been isolated; however, it has been suggested that SAPX leading sequence makes it possible to allocate SAPX between the chloroplast and mitochondrion. Two to three cytosolic APX (cAPX) are present in plant cell cytosol. Peroxisomal APX (pAPX) is not only highly similar to cAPX but also to tAPX, as it is equipped with a hydrophobic docking domain at the $\mathrm{C}$ terminus. pAPX is anchored to the peroxisomal membrane with its catalytic domain facing the cytosol (Bunkelmann and Trelease 1996; Del Rio et al. 1998; Ishikawa and Shigeoka 2008).

MDHAR and APX, bound to the peroxisomal membrane, play a dual role in peroxisomal metabolism. Firstly, they participate in the reoxidation of the NADH pool in order to meet the requirements of peroxisomal metabolism for $\mathrm{NAD}^{+}$. Secondly, directly related to pAPX activity, they also have protective function in preventing $\mathrm{H}_{2} \mathrm{O}_{2}$ leaking out of the peroxisome to the cytosol or scavenging $\mathrm{H}_{2} \mathrm{O}_{2}$ formed at the cytosolic surface of the peroxisomal membrane by $\mathrm{O}_{2}{ }^{-}$disproportionation (Del Rio et al. 1998, 2002).

Sugar beet is an important crop plant, which is able to survive under high salt concentrations. Despite the economic importance of sugar beet, the principal components of the antioxidative enzyme system are not yet characterized in this plant, and their role in the mechanism of tolerance against salinity remains unclear. This study was undertaken to isolate the gene coding for peroxisomal isoform of APX from sugar beet and investigate its expression patterns during adaptation to high salinity.

\section{Materials and Methods}

\section{Plant Material and Stress Treatment}

Wild salt-tolerant beet Beta vulgaris ssp. maritima, and two cultivars of sugar beet Beta vulgaris, cv. Janosik and Huzar were used as the plant material. The seeds were sown into pots filled with sand and vermiculite (v/v), and grown under greenhouse conditions $\left(16 \mathrm{~h} / 8 \mathrm{~h}\right.$ photoperiod; $\left.25 \pm 2{ }^{\circ} \mathrm{C}\right)$. They were watered regularly with half-strength Hoagland solution.

Two salinization protocols, i.e. long-term and short-term treatments, were employed. For the long-term treatment, potted plants were subjected to either moderate or severe salt stress during a 32-day culture period. Moderate or severe salt stress was imposed as described by Bor et al. (2003) with modifications, by watering the plants with half-strength Hoagland medium supplemented with 150 - or $300 \mathrm{mM}$ $\mathrm{NaCl}$, respectively. Plants watered with unsupplemented, half-strength Hoagland medium were used as a control. Plants were watered every 2 days, with $200 \mathrm{ml}$ of solution per $2 \mathrm{~L}$ of sand/vermiculite mixture. Salt treatment was initiated when the first pair of true leaves emerged and the culture was continued for 32 days. Leaves, representing the pair of first true leaves were collected for analysis at $0,4,8,16,24$, and 32 days after the beginning of the treatment. Plants representing three beet genotypes were chosen for long-term treatment experiments: a wild species B. vulgaris ssp. maritima and two cultivars of sugar beet: Huzar and Janosik.

In order to assess salt exposition, soil conductivity was measured at regular intervals during the treatment period. The conductivity was measured in $10 \mathrm{ml}$ of soil sample suspended in $50 \mathrm{ml}$ of distilled water using a CPC-505 conductivity meter (Elmetron).

For the short-term treatment, the first true leaves representing the Huzar cultivar were excised, transferred to dishes containing half strength Hoagland solution $(200 \mathrm{ml})$ supplemented with 0 (control), $150 \mathrm{mM}$ (moderate salt stress) or $300 \mathrm{mM}$ (strong salt stress) $\mathrm{NaCl}$. Detached leaves were left floating in the incubation medium under constant white light irradiation, at $25 \pm 2{ }^{\circ} \mathrm{C}$, for $18 \mathrm{~h}$. Leaf samples were collected for analysis every $2 \mathrm{~h}$, until the 18th hour of incubation.

The collected leaves were frozen in liquid nitrogen, and stored at $-80{ }^{\circ} \mathrm{C}$ until RNA or genomic DNA extraction for subsequent cloning or Q-RT-PCR analysis. Leaf samples for ASC, $\mathrm{H}_{2} \mathrm{O}_{2}$, APX, or LOOH determination were subjected to analysis immediately after harvesting.

RNA Isolation and cDNA Synthesis

Total RNA was isolated from leaf samples using TriPure reagent (Roche). Total RNA preparations were subjected to DNase treatment, which was carried out using a DNase Kit (Roche), according to the manufacturer's instructions. RNA quantity and 
quality were determined using a NanoDrop 1000 (Thermo Scientific) spectrophotometer and by agarose gel electrophoresis. First-strand cDNA was synthesized from $1 \mu \mathrm{g}$ of total RNA using random primer and SuperScript III Reverse Transcriptase (Invitrogen), following the manufacturer's instructions.

\section{Isolation and Cloning of $B v \mathrm{pAPX} \mathrm{cDNA}$}

In order to isolate fragments of the APX coding sequence from beet leaf cDNA, several pairs of degenerated primers (Table S1) were designed on the basis of conserved regions of APX sequences from different plant species available in the GenBank database (http://www.ncbi.nlm.nih.gov/genbank/). PCR was performed, using a MasterCycler Gradient (Eppendorf) thermal cycler, on the cDNA templates from leaves of long-term salt-treated plants. Fragments of transcript encoding beet ascorbate peroxidase were amplified from reverse-transcribed total RNA using degenerate PCR primers complementary to the conserved regions of the APX coding sequence. Each PCR reaction $(20 \mu \mathrm{l})$ contained $0.25 \mathrm{mM}$ of the dNTPs, $2 \mu \mathrm{l} 10 \times$ PCR buffer, 0.6 U DyNAzyme II polymerase (Finnzymes), and $1 \mu \mathrm{l}$ cDNA template; primer concentrations varied depending on the primer's degeneracy. Samples were heated for $3 \mathrm{~min}$ at $95^{\circ} \mathrm{C}$, and then were subjected to 40 cycles of $30 \mathrm{~s}$ at $95^{\circ} \mathrm{C}, 30 \mathrm{~s}$ at $50^{\circ} \mathrm{C}$, and $30 \mathrm{~s}$ at $72^{\circ} \mathrm{C}$, followed by an additional $4 \mathrm{~min}$ at $72^{\circ} \mathrm{C}$. The PCR products were separated on $2 \%$ agarose gel; the candidate gel bands were excised, subjected to column purification using a PCR product purification kit (Roche) and cloned into a pGEM-T vector (Promega). Subsequently, the ligation product was introduced into E. coli strain JM109 via the heat-shock method. Sequencing of independent clones was performed on both strands at the Institute of Biochemistry and Biophysics, Polish Academy of Sciences, Warsaw, Poland.

In order to obtain a full-length sequence of cDNA, 3 ' and 5 ' ends of $B v$ pAPX cDNA were synthesized by RACE-PCR using a 5'/3' RACE Kit (Roche). The gene-specific primers (Table S1) were designed on the basis of the sequence of the cDNA fragments. The 5'RACE and 3'RACE fragments were cloned and sequenced as described above.

\section{Cloning the Promoter and Genomic Sequence of $B v \mathrm{pAPX}$}

Genomic DNA was isolated from beet leaves using the CTAB method. The BvpAPX genomic clone was isolated employing the procedure described by Kavitha et al. (2008). Briefly, $B v$ pAPX genomic fragments of $1,777,413$, and 221 bp were amplified using primers corresponding to different regions of $B v$ pAPX cDNA (Table $\mathrm{S} 1$ ). PCR products were ligated to pGEM-T plasmid, cloned in E. coli, sequenced, and compared with the $B v \mathrm{pAPX}$ cDNA sequence.

The 5'UTR region of $B v \mathrm{pAPX}$, containing a promoter region, was isolated from beet genomic DNA by 5'RACE
PCR using a 5'/3' RACE Kit (Roche). Firstly, genomic DNA was digested with Sau3AI restriction exonuclease to produce approximately $20-\mathrm{kbp}$ restriction fragments. Restriction fragments were used as a template in the 5' RACE. Primers used for $B v \mathrm{pAPX}$ promoter isolation by RACE are listed in Table S1. Firstly, homopolymeric polyA sequences were added to restriction fragments in a terminal transferasecatalyzed tailing reaction. Then, the promoter region was amplified by PCR with a BvpAPX-specific starter and an oligo(dT) starter (Table S1). PCR products were ligated to pGEM-T plasmid, cloned in E. coli, and sequenced. Clones containing the promoter sequence were identified by comparing them to a 5' end of a $B v$ pAPX cDNA sequence.

\section{Bioinformatic Tools and Phylogenetic Analyses}

Multiple sequence alignments were performed using a CLC Sequence Viewer and ClustalW2 software (http://www.ebi.ac. uk/Tools/msa/clustalw2/). Nucleotide and amino acid sequences of $B v \mathrm{pAPX}$ were compared with those in the GenBank database using BLAST. Potential regulatory elements in the promoter sequence were identified using the programs PlantPAN (Chang et al. 2008), PLACE (Higo et al. 1999), PlantCARE (Lescot et al. 2002), and TRANSFAC (Patch 1.0) (Matys et al. 2003). The genomic sequence of $B v \mathrm{pAPX}$ was analyzed using the Splign program (Kapustin et al. 2008). The transmembrane domain was predicted using TopPred 0.01 online software (http://mobyle.pasteur.fr/cgibin/portal.py?\#forms::toppred) (Claros and von Heijne 1994). The phylogenetic tree was constructed based on amino acid sequences using the neighbour joining method with 1,000 bootstrap replication using MEGA 5.0 software.

\section{Gene Expression Analysis via Quantitative PCR}

The expression of the $B v \mathrm{pAPX}$ gene in beet leaves was analyzed via Q-RT-PCR. To ensure the accuracy of the quantification, we normalized $B v \mathrm{pAPX}$ expression to the reference transcript encoding actin (GenBank: Accession no. HQ656028.1). PCR reactions were performed in a total volume of $20 \mu$ using a Dynamo Flash QPCR kit (Finnzymes) in a Mastercycler ep realplex gradient (Eppendorf). Sequences of gene-specific primers used for Real Time PCR are included in Table S1. PCR was initiated with 3 min of initial denaturation at $95^{\circ} \mathrm{C}$, followed by 40 cycles of $30 \mathrm{~s}$ at $95^{\circ} \mathrm{C}, 30 \mathrm{~s}$ at $59^{\circ} \mathrm{C}$, and $15 \mathrm{~s}$ at $72{ }^{\circ} \mathrm{C}$, then a final extension for $4 \mathrm{~min}$ at $72{ }^{\circ} \mathrm{C}$. SYBR Green fluorescence was recorded after the elongation step of each cycle. The specificity of the amplifications was checked via melting curve analysis performed by heating the samples from 70 to $95{ }^{\circ} \mathrm{C}$ with temperature increments of $0.1{ }^{\circ} \mathrm{C}$ and simultaneous fluorescence detection. To ensure that the PCR products were generated from cDNA and not the genomic DNA, proper control reactions were carried out 
without reverse transcriptase treatment. The reaction threshold cycle $(C t)$ values were determined using realplex 2.2 software. Reactions were carried out in triplicates and blank controls without cDNA template were included in every experimental set-up. The specificity of PCR was verified by sequencing.

The mRNA levels of $B v$ pAPX and actin in leaves were determined using the absolute quantification method according to Wawrik et al. (2002). The method consisted of comparing sample $C t$ values with standard curves based on cRNA standard samples. In order to prepare the standard samples, the recombinant plasmids pGMT/actin and pGMT/ $B v \mathrm{pAPX}$ were constructed and subcloned in E. coli. Plasmid mini-preparations were used as a template to prepare cRNA. First, in order to produce RNA standards, plasmids were linearized with ScaI, and in vitro transcriptions were performed using T7 RNA polymerase (Roche). Next, RNA was digested for $15 \mathrm{~min}$ with DNase I (Roche) to eliminate DNA contamination. Subsequently, RNA was purified by phenol/chloroform extraction and quantified with a spectrophotometer (NanoDrop 1000; Thermo Scientific). Actin cRNA and BvpAPX cRNA were 10-fold serially diluted to generate a series of cRNA solutions ranging from $10^{1}$ to $10^{6} \mathrm{pg} / \mu \mathrm{l}$. cRNA preparations were reverse transcribed to generate final cDNA standards. The standards were used as an amplification template to construct standard curves by plotting the logarithm of plasmid concentration (pmol) against the $C t$ value. Thereafter, the concentrations of actin or $B v$ pAPX cDNA in the tested samples were calculated by comparing the sample $C t$ to the proper standard curve.

\section{APX Activity and Biochemical Parameters in Crude Plant Extracts}

The activity of ascorbate peroxidase (APX) and ascorbic acid (ASC) concentrations were determined as described previously (Tyburski et al. 2009). Quantification of lipid hydroperoxides (LOOH) was analyzed using a modified ferrous ion oxidation-xylenol orange assay (FOX2), according to DeLong et al. (2002). To determine the $\mathrm{H}_{2} \mathrm{O}_{2}$ concentration, leaf samples $(0.5 \mathrm{~g})$ were homogenized in liquid nitrogen and the powder was extracted in $5 \mathrm{ml} 0.1 \%$ TCA at $4{ }^{\circ} \mathrm{C}$. The homogenate was centrifuged at $10,000 \mathrm{~g}$ for $10 \mathrm{~min}$ at $4{ }^{\circ} \mathrm{C}$ and the supernatant was neutralized with $4 \mathrm{~N} \mathrm{KOH}$ to $\mathrm{pH} 7.5$ and centrifuged again at $10,000 \mathrm{~g}$ at $4{ }^{\circ} \mathrm{C}$ for $1 \mathrm{~min}$. The $\mathrm{H}_{2} \mathrm{O}_{2}$ concentration was measured with the peroxidase-coupled assay (DMAB-MBTH-POX method), according to VeljovicJovanovic et al. (2002).

\section{Statistics}

Statistical differences between the mean values were determined with the Student's $t$ test. Differences at the level of $P<0.05$ were considered significant. Three biological repetitions of each experiment were performed. The figures show the representative results for each experiment. Mean and standard deviations were calculated. Error bars shown in all the figures represent standard deviations (SD).

\section{Results}

\section{$B v \mathrm{pAPX}$ Gene Structure}

The full-length cDNA and genomic sequence of sugar beet peroxisomal ascorbate peroxidase $(B v \mathrm{pAPX})$ was isolated using the RT-PCR and RACE approach. Amplified fragments of pAPX transcript were cloned, sequenced, and assembled to obtain the complete sequence of pAPX cDNA. Then, PCR primers specific to the pAPX transcript were used to amplify the overlapping clones from genomic DNA representing the genomic sequence of the sugar beet pAPX gene. Concurrently, the 5'UTR region of $B v \mathrm{pAPX}$, containing a promoter region, was isolated from beet genomic DNA using 5'RACE PCR.

The 1,262-bp full-length cDNA exhibited one open reading frame (ORF) composed of $858 \mathrm{bp}$. ORF started with an ATG codon at position 146 and terminated with a stop codon (TAG) at position 1004. The coding sequence was flanked with a 417-bp 5'UTR and a 260-bp 3'UTR. A putative polyadenylation signal was found at the 3 ' end of the cDNA. Analysis of the genomic sequence corresponding to the cDNA of $B v$ pAPX revealed a gene $(2,536 \mathrm{bp})$ consisting of 5 exons and 4 introns (Fig. 1). For all the exons, the intronexon splice junctions were readily identifiable and conformed to the consensus sequence GT at the donor site and AG at the acceptor site. The $B v$ pAPX gene sequence was submitted to the GenBank (Accession. No. JX912251).

\section{Analysis of the $B v \mathrm{pAPX}$ Promoter Region}

The $B v$ pAPX upstream regulatory region was analyzed using four cis-element recognition programs (see "Material and Methods"). Both core promoter elements as well as several stress-responsive, regulatory sequence motives were predicted from the 5'UTR region of the BvpAPX gene isolated in this study. Two elements of the core promoter, namely TATA and CAAT (Molina and Grotewold 2005), were predicted. The $B v$ pAPX promoter was characterized by the presence of a TATATA hexamer at $-176 \mathrm{bp}$ from the start codon. In the $B v$ pAPX promoter, the CAATT box was localized $-208 \mathrm{bp}$

Fig. 1 The nucleotide and the deduced aminoacid sequence of $B v$ pAPX. Start codon ATG is indicated in bold. The characteristic domains in putative protein sequence are marked with gray enzyme active site, dark gray heme binding motive, underline transmembrane domain, double underline peroxisomal targeting sequence. Intron sequences are indicated by italic. The termination codon is marked with an asterisk. $(\mathrm{A})_{\mathrm{n}}$ - poly(A)sequence 
GACCACGCGTATCGATGTCGACTTTTTTTTTTTTTTTGAGTAGCATTTAGTTAGACTTTC 60 СTCTACATTTCTTTATAGTTAAAATTTACAACAATTTGCCATCGAACATTTCAAATTACT 120

121 TATTACTGAAACTAAATTAAAAAAAAAGTTGCGTGTGACATTTTGTCAATTTATACTCTC 180 AAGAAAAGCATATAAATATATTATCCAACAATTATCTTGAAATTAAAAAAAAGAGCATGA 240 TATATATTTAAGAAATTAATGCTTTGGCAATTGCCAAGTGCCAACAGCTGAAAAGCCCAG 300 AGGTTTTATCTTCAACTGAAAAATACCCAATTGCTTGCATTTTAGCAACCAATATCTTCT 360

361 CTTTCTCTCTCCTCTCCTTAACACAGAGTGACCACTGATTCTGAAGAAGCTCCAACAATG 420 $\mathrm{M}$

421 GCGATGCCAGTAGTTAACACAGAGTACCTTAAAGAAATCGACAAAGCTCGTCGCGATCTT 480 $\begin{array}{llllllllllllllllllll}A & M & P & V & V & N & T & E & Y & L & K & E & I & D & K & A & R & R & D & L\end{array}$

481 CGCGCACTCATCTCTAATCGCAATTGCGCTCCTATTATGCTCCGCCTCGCGTAACTTTCT 540 $\begin{array}{llllllllllllllllll}R & A & L & I & S & N & R & N & C & A & P & I & M & L & R & L & A\end{array}$

541 CTCTCTCCTTTGACTTCTCTTTCATCTCGTCCGAATTCTCTCTCTTACTTTGATTTTTCT 600

601 ATCTATCTCTCTCTAGGTGGCATGATGCAGGGACGTATTGCGCCAAGACCAAGACTGGTG 660 $\begin{array}{llllllllllllllllllll}W & H & D & A & G & T & Y & C & A & K & T & K & T & G\end{array}$

661 GTCCGAATGCTTCCATTCGGAATGATGAAGAGTGCGCTCATGGTGCTAATAATGGTTTGA 720 $\begin{array}{lllllllllllllllllllll}G & P & N & A & S & I & R & N & D & E & E & C & A & H & G & A & N & N & G & L\end{array}$

721 AGAAAGCTATTGATTGGTGTGAGGAGGTGAAGTCTAAACACCCAAAAATTACTTATGCAG 780 $\begin{array}{llllllllllllllllllll}K & K & A & I & D & W & C & E & E & V & K & S & K & H & P & K & I & T & Y & A\end{array}$

781 ACCTCTATCAGCTTGCTGGCGTTGTTGCAGTCGAGGTCACCGGAGGACCTACTGTTGACT 840 $\begin{array}{llllllllllllllllllll}D & L & Y & Q & L & A & G & V & V & A & V & E & V & T & G & G & P & T & V & D\end{array}$

841 TTGTTCCTGGTAGAAAGGACTCAAATGTGTGTCCCAAAGAAGGACGACTTCCAGATGCCA 900 $\begin{array}{llllllllllllllllllll}F & V & P & G & R & K & D & S & N & V & C & P & K & E & G & R & L & P & D & A\end{array}$

901 AACAAGGTGCACCACATTTGAGGGACATATTCTATAGGATGGGTCTCACTGACAAAGACA 960 $\begin{array}{lllllllllllllllllllll}K & Q & G & A & P & H & L & R & D & I & F & Y & R & M & G & L & T & D & K & D\end{array}$

961 TTGTGGCCCTGTCCGGGGGTCATACCCTGGTAATATTCTTTCTGTCTTTATCAGCATTTC 1020 I $\quad V \quad A \quad A \quad S \quad G \quad G \quad H \quad T \quad L$

1021 CTTGCCACTGGGATGTGCACTTAATGTCTGGCTGTGCTTTTGGTGACATAGGGAAGGGCA 1080 G $R \quad A$

1081 CATCCAGAGAGGTCAGGCTTTGATGGCCCATGGACCCAGGATCCGCTCAAGTTTGATAAC 1140 $\begin{array}{llllllllllllllllllll}\mathrm{H} & \mathrm{P} & \mathrm{E} & \mathrm{R} & \mathrm{S} & \mathrm{G} & \mathrm{F} & \mathrm{D} & \mathrm{G} & \mathrm{P} & \mathrm{W} & \mathrm{T} & \mathrm{Q} & \mathrm{D} & \mathrm{P} & \mathrm{L} & \mathrm{K} & \mathrm{F} & \mathrm{D} & \mathrm{N}\end{array}$

1141 TCCTATTTTCTGTAAGAGATGTTATTGTTTTTTTTGTGTGTGCGGTTTTACCTTAGAGAA 1200 $\begin{array}{lllllll}S & Y & F & L\end{array}$

1201 GTTGAGCCACTGGGTTGAGTCTCTTCTGTACAAAAGGTTAATGCCATTTAACATCTTTGA 1260 1261 TTCTTGGCTCACCAGGGAGCTATTAAAAGGAGAATCAGAAGGACTGTTGCAACTTCCTAC 1320 $\begin{array}{lllllllllllllllllll}E & L & L & K & G & E & S & E & G & L & L & Q & L & P & T\end{array}$

1321 TGATAAAACTTTGGTGGAGGATCCTGCATTTCGCCCTTTTGTGGATCTGTATGCTAAGGT 1380 $\begin{array}{llllllllllllllllllll}D & K & T & L & V & E & D & P & A & F & R & P & F & V & D & L & Y & A & K\end{array}$

1381 ACTTAACCTGACTTTTGAATGCTGCAACATTTTGCTTTTTTGAGCTTCTTGTATATGGCT 1440

1441 TGAAGTGTAAGCCCCTATTCTTTGGGCACAGTTTCAGTTCAGTTCAGTTCAGCTCCTTTC 1500

1501 AGTTTAGTTCAGCTACCTTCTTCTCACAGTTTTACTTCAGTTCAGTTGGGCTTGTTTCAG 1560

1561 TTCAGTTCAGCCCAGCCCAAAAGAACAGGGTCTAAGTGTTGACATGAATTTTATGGAAAT 1620

1621 TGTCTACAGCATTCCGTTAGTAGTTGTGTTCAGTCTGGAAGTTCTTGATTGTTGCACGCT 1680

1681 TGTTTGCCTAAAGTGTTTCTTGCAGTAAAGTATTACTTGCTGATTGAAAAAGACAAAAGG 1740

1741 ATGCTGTTCAACTGTCACATAATCATGTTTATCAGTCAATCTTTTTTGTGATCTAAGTTT 1800

1801 CAACATGGAATCTCCTGATTGTTGTCTAAAATTAGTCATCTTCCTAAATTTTGCTTGGTG 1860

1861 ATAAAAAATGCTGAATAAGGAGTCAGAAATATTCCCCCAGAATTGTAGATCAGTTAATAT 1920

1921 TTGTCATCAAAGTGCTTTTACTGATTGTTTGGGACATGAATTGCAATATGTTGCACCGAG 1980

1981 TCATTACTCTATTGCTTAGTTCTCTAGAAATGTGGTGGCTGAAGCCATGGAATCCCCTGA 2040

2041 TAAAGACTTTTTCAGCTACTGTTGCGGTGCTACTGTTTTCTGCGGGGTTGGCTATCTTCT 2100

2101 TTATGTTTATTAGATTCACCTCGTTCCAATCTACTCTGAATTTGGGATCTAGATTCTAGA 2160

2161 CATCACTGCTAATGATAGGTAAATTCCTTTTGATGAATACTGAGGCAACAAATTTCTAAC 2220

2221 TTTTGGCATTCTCCTATATAATTTGCATTAGAATTTAGGTAGCAGGATTCTTTGTTTGGA 2280

2281 TTCCCTTCAAACAAGTCACTCTTCCATTGATCAAATCAGATATTTTTACCTGGTAGTCAT 2340

2341 ATCCCGTGCTAATAAAATTGGATATGTGACCAAAATTTGACCCAATTATCATAATTATCT 2400

2401 GCGATTATTATATGCTTCACATAAAAAATCGACCTGTTGACCCAATATGACCAGCTCTAC 2460

2461 TAGGGGTAAATGTCTGTATTCCACTCTTTTCTGTAAAGATCGTATACTCAATAGTTCTTG 2520

2521 GTGTCAGGATGAGGAGGCCTTCTTCCGGGACTATGCTGCCTCACACAAGAAACTTTCAGA 2580 $\begin{array}{llllllllllllllllll}D & E & E & A & F & F & R & D & Y & A & A & S & H & K & K & L & S & E\end{array}$

2581 ACTAGGATTTACTCCTAGTATTGGGGCCAAGTCTCCCAAGGACAGCACTGTATTGGCCCA 2340 $\begin{array}{llllllllllllllllllll}L & G & F & T & P & S & I & G & A & K & S & P & K & D & S & T & V & L & A & Q\end{array}$

2341 GAGTGCTGTTGGAGTTGCAGTTGCTGCAGCAGTAGTCATTCTGAGCTACATCTATGAAGC 2400 $\begin{array}{llllllllllllllllllll}\mathrm{S} & \mathrm{A} & \mathrm{V} & \mathrm{G} & \mathrm{V} & \mathrm{A} & \mathrm{V} & \mathrm{A} & \mathrm{A} & \mathrm{A} & \mathrm{V} & \mathrm{V} & \mathrm{I} & \mathrm{L} & \mathrm{S} & \mathrm{Y} & \mathrm{I} & \mathrm{Y} & \mathrm{E} & \mathrm{A}\end{array}$

2401 TCGTAAGCGTGTGTAGAAGAGAGATTATACAAGTAAACACCATTCATATCCATTACATAT 2460 $\begin{array}{lllllll}R & K & R & V\end{array}$

2461 AGTCTGTATGAATTAGTTACATCATGTATTCCAAGTTTATTGCTTATACTGTTTTTCACA 2520 2521 GCTAGCCATCTAGGTATATATGCAACCTTACCAGCTAATGTTATTTCTACCTTAAATGAT 2580 2581 GAACTGTTAGATTTCACAATAAGAGTAAAATAAGTTTGCTTTGGGGCTCCTGTACT (A) n 2536 
upstream from the start codon (Table S2). Among stressresponsive elements, the following were found: an MYBbinding motif (Abe et al. 2003), an ethylene responsive element (ERE) (Rawat et al. 2005), an ABA-responsive element (ABRE) (Kaplan et al. 2006), a WRKY transcription factor binding motif (Chen and Chen 2000), and a binding site for the BELL1-like homeobox protein BELLRINGER (BLR) (Bao et al. 2004). Putative regulatory elements predicted in the 5' upstream region of BvpAPX are listed in Table S2.

Structure and Phylogenetic Analysis of the BvpAPX Protein

The predicted ORF of the $B v \mathrm{pAPX}$ gene encodes a protein composed of 285 amino acids, having a molecular weight of $31.2 \mathrm{kDa}$ with a predicted $p \mathrm{I}$ of 7.05. Several motifs essential for the enzymatic activity of APX were detected in the deduced amino acid sequence (Fig. 1). Two strongly conserved domains representing an enzyme active site and a heme-binding domain were predicted at positions $31-43$ and $152-160$, respectively. Segments characterized by XANX, LPDAX, and (E)RSGF, which are assumed to be essential for the interaction of ascorbate peroxidase with ascorbate (Jespersen et al. 1997), were present in BvpAPX sequences at residues 68-71, 130134 , and 168-172, respectively. These peptide segments form the surface of the active site entrance channel near the heme edge of ascorbate peroxidase (Jespersen et al. 1997). A membrane-spanning domain encompassing 20 amino acids, between residues 259 and 279, was identified at the Cterminal end of the deduced polypeptide sequence. The predicted transmembrane domain is followed by a cluster of positively charged amino acids (RKRV) at the C-terminal end of the protein, which constitute a putative peroxisometargeting signal (Fig. 1). This motif, together with the transmembrane domain, is sufficient to target an APX protein from the cytosol to peroxisomes via the peroxisomal endoplasmic reticulum ER (Mullen and Trelease 2000). The aforementioned features of the C-terminal end of the protein indicate that an isolated gene is supposed to encode a peroxisomal APX.

The predicted amino acid sequence of $B v \mathrm{pAPX}$ was aligned and compared with ascorbate peroxidase sequences from several plant species (Fig. S1). Multiple alignment analysis performed on the deduced obtained amino acid sequence of the BvpAPX and APX protein sequences from several species revealed a high degree of similarity throughout most of the sequence length, with few variable regions preferentially localized near the $C$ terminal (Fig. S1). BvpAPX revealed the strongest similarity to the APX sequences from halophytic plants: Salicornia brachiata and Mesembryanthemum crystallinum with a similarity score of 87.7 and $86.3 \%$, respectively.

A phylogenetic tree was constructed on the basis of the $B v \mathrm{pAPX}$ and other plant pAPX using CLUSTAL $\mathrm{W}$ and MEGA 5.0 (Tamura et al. 2011) software. The tree depicted that $B v \mathrm{pAPX}$ belongs to the plant ascorbate peroxidase family and is most closely related to pAPX from Salicornia brachiata and, together with APX proteins from Salicornia and Mesembryathemum, forms a separate branch on the phylogenetic tree. Enzymes clustered in this branch are related to APX proteins from leguminous species, such as Medicago truncatula, Vigna unguiculata and Glycine max (Fig. 2).

\section{Expression Patterns of BvpAPX Under Salt Stress}

Two salinization protocols, a long-term and a short-term treatment, were applied to assess the BvpAPX expression in beet leaves, as described in "Materials and Methods". Measurements of soil conductivity revealed that the concentration of soluble salts progressively increased in the soil during long-termtreatment in a concentration-dependent manner (Fig. S2). Plants representing three beet genotypes were chosen for longterm treatment experiments: a wild species $B$. vulgaris ssp.

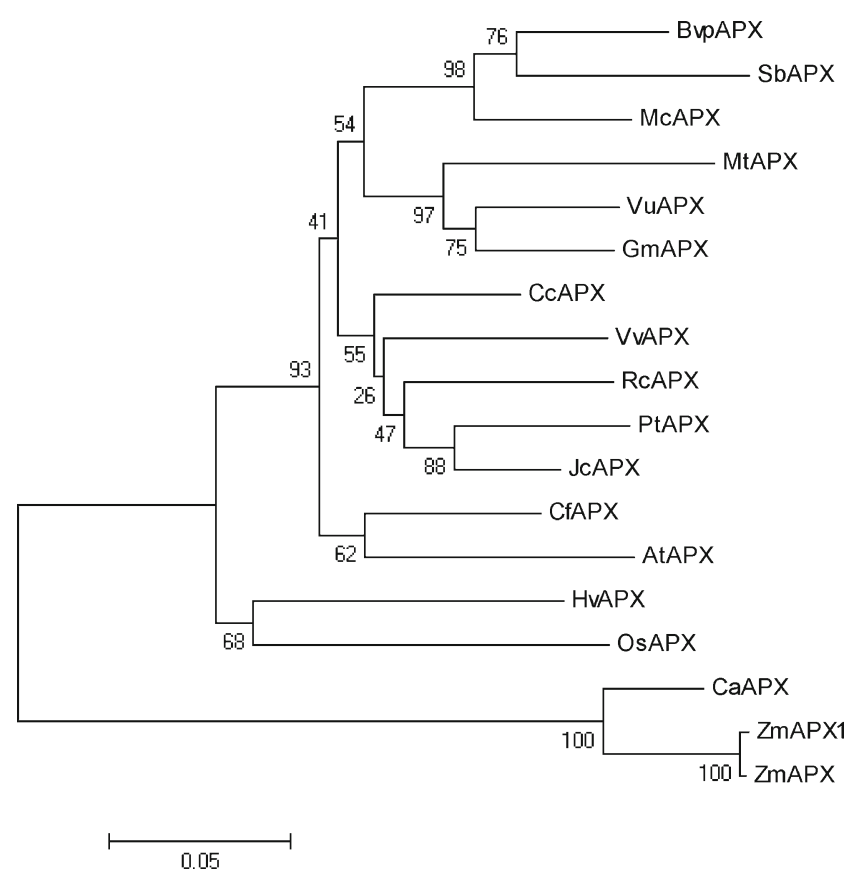

Fig. 2 Phylogenetic tree among different species that was constructed based on deduced amino acid sequences by neighbor-joining method with 1,000 bootstrap replication using MEGA 5.0 software. The parameters pairwise deletion and $\mathrm{p}$-distance amino acid substitution model were used. GenBank accession numbers of amino acid sequences used: BvpAPX (AGA20371; Beta vulgaris), SbAPX (ACI15209; Salicornia brachiata), McAPX (AAD30294; Mesembryanthemum crystallinum), CfAPX (AFS49700; Capsicum frutescens), JcAPX (ACT87980; Jatropha curcas), VuAPX (AAS46016; Vigna unguiculata), RcAPX (XP_002530823; Ricinus communis), MtAPX (XP_003607199; Medicago truncatula), VvAPX (XP 002278281; Vitis vinifera), GmAPX (XP_003537806; Glycine max), HvAPX (BAB62533; Hordeum vulgare subsp. vulgare), CaAPX (ABP65326; Cenchrus americanus), ZmAPXI (NP 001152249; Zea mays),ZmAPX (NP 001152746; Zea mays), OsAPX (CAD39836; Oryza sativa), AtAPX' (CAA06823; Arabidopsis thaliana), CcAPX (BAB64351; Cucurbita cv. Kurokawa Amakuri), PtAPX (AAV58827; Populus tomentosa) 
maritima and two cultivars of sugar beet (Huzar and Janosik). For short-term treatment, detached leaves representing the Huzar cultivar were placed in a medium supplemented with either moderate or high salt concentrations and collected for analysis every $2 \mathrm{~h}$ until the 18th hour of incubation. Both approaches included controls that were not treated with salt stress.

$B v \mathrm{pAPX}$ expression in leaves of plants subjected to longterm salt treatment increased in a salt-dependent manner in all three genotypes. However, the duration of changes in transcript level varied between the genotypes. $B v \mathrm{pAPX}$ transcript levels in leaves of salt-treated B. vulgaris ssp. maritima plants were comparable to that of the controls on the $4,8,16$ and 24 day of treatment. On the other hand, a significant increase in $B v \mathrm{pAPX}$ expression was observed after 32 days of treatment with $300 \mathrm{mM} \mathrm{NaCl}$ (Fig. 3a). A salt-dependent increase in BvpAPX transcript level in cv. Huzar was observed after 8, 16 and 32 days of treatment, whereas on the 4th and 24th days of treatment, leaves of salt-treated plants and control plants did not show any significant difference with respect to $B v \mathrm{pAPX}$ expression (Fig. 3b). BvpAPX expression in leaves of cv. Janosik was up-regulated due to salinity when assayed on the 16,24 or 32 day of the treatment. However, the expression level remained unaffected by salinity on the 4 or 8 day of the treatment (Fig. 3c). Among all the tested beet genotypes, saltinduced up-regulation of $B v \mathrm{pAPX}$ transcript levels was larger in the plants treated with $300 \mathrm{mM} \mathrm{NaCl}$ in comparison to $150 \mathrm{mM} \mathrm{NaCl}$ treatment (Fig. 3).

Changes in the level of $B v$ pAPX transcript were also observed in control plants. A slight decrease in transcript level was detected on days 4 and 8 in B. vulgaris ssp. maritima. During the remaining part of the culture period, $B v \mathrm{pAPX}$ expression slightly increased (Fig. 3a). Control plants of cultivar Huzar displayed an initial increase in BvpAPX expression level, observed on day 4 , followed by a period marked by lower expression levels (Fig. 3b). BvpAPX expression in cultivar Janosik was stable throughout the first 8 days of culture. Thereafter, expression levels declined (Fig. 3c). Analysis conducted after 32 days of culture revealed that $B v$ pAPX expression rose again in both cultivars (Fig. 3b, c).

Application of salt stress to the excised leaves either reduced or completely eliminated the protective effects of several mechanisms regulating $\mathrm{Na}^{+}$delivery to the shoot and enhanced the exposure of the photosynthetic apparatus to salinity treatment (Smethurst et al. 2009). Therefore, the $B v$ pAPX expression levels were analyzed in excised leaves, under short-term treatment conditions with moderate or high salinity. We incubated detached leaves, obtained from young sugar beet plants, in the media supplemented with salt concentrations for several hours. BvpAPX expression level was assessed at regular intervals during the incubation time (Fig. S3). It was noted that $B v$ pAPX expression levels remained unaffected throughout the majority of the 18 -h
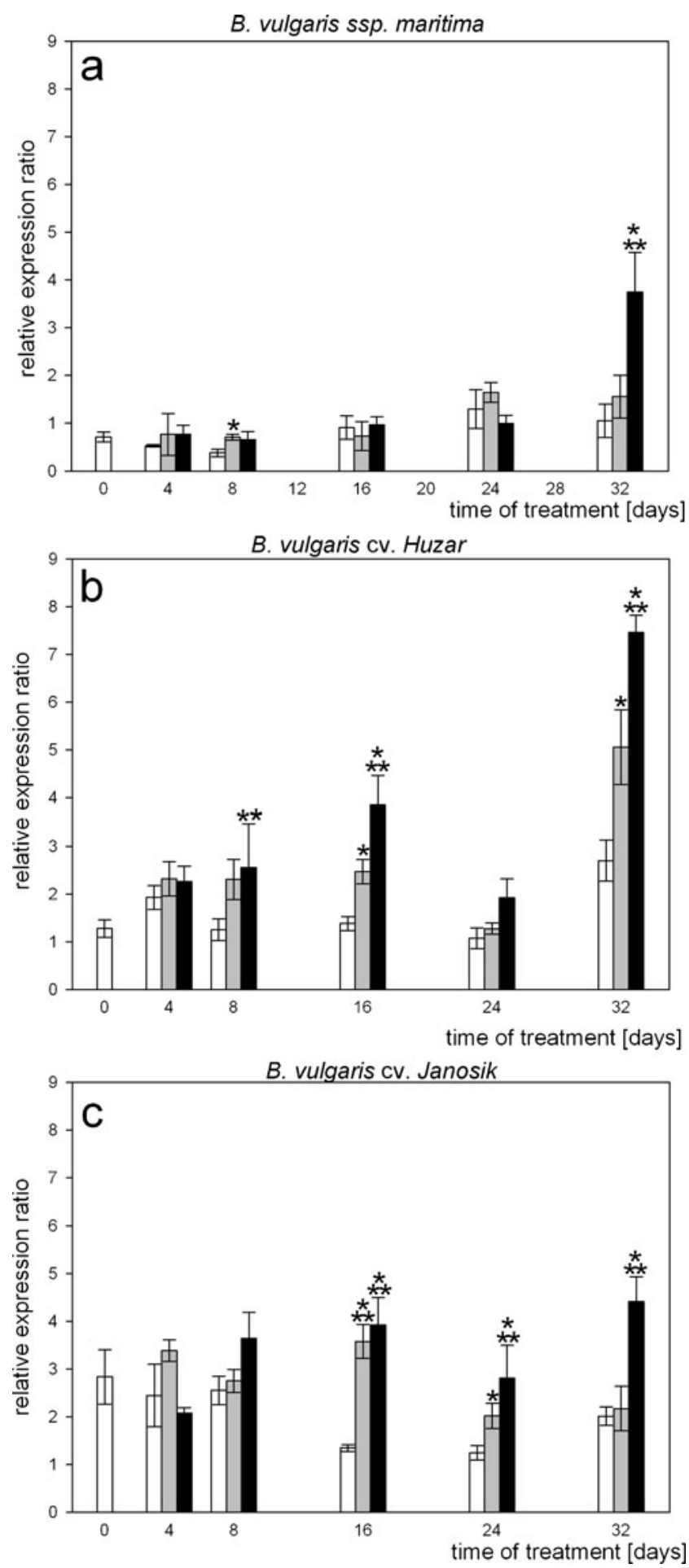

Fig. 3 Expression of BvpAPX measured in leaves of $B$. vulgaris ssp. maritima (a), B. vulgaris cv. Huzar (b) and B. vulgaris cv. Janosik (c) subjected to long-term salt stress. Relative transcript level was determined in leaves of unstressed (control) plants (white bars), plants treated with moderate $(150 \mathrm{mM} \mathrm{NaCl})$ salt stress (gray bars) or strong $(300 \mathrm{mM}$ $\mathrm{NaCl}$ ) salt stress (black bars). Asterisk denotes significant differences from control with $p<0.05$. Double asterisk denotes up-regulation $(>2.0-$ fold) of the gene with respect to control 
incubation period. $B v \mathrm{pAPX}$ expression in leaves subjected to moderate salinity did not differ from the control throughout the culture period. However, a slight increase in BvpAPX expression level was observed in leaves exposed to high salinity after 16 and $18 \mathrm{~h}$ of incubation (Fig. S3).

Ascorbic Acid (ASC), $\mathrm{H}_{2} \mathrm{O}_{2}$, and $\mathrm{LOOH}$ Concentrations and APX Activity in Leaves of Sugar Beet Cultivars and $B$. vulgaris ssp. maritima Under Salt Stress Conditions

In order to find out whether salt stress-induced changes in $B v \mathrm{pAPX}$ expression levels are correlated with alterations in the cellular redox system, we analyzed selected redox parameters in leaves of the control plants and long-term or shortterm salt-treated plants. Among the components of the leaf redox system, endogenous levels of APX substrates, i.e. ASC and $\mathrm{H}_{2} \mathrm{O}_{2}$, were determined. Furthermore, total APX activity and $\mathrm{LOOH}$ content were also measured.

Leaves of plants representing all three genotypes subjected to long-term treatment with salinity accumulated higher concentrations of ASC compared to the control plants (Fig. 4a-c). However, important changes in leaf ASC levels were also observed in the untreated control. All the analyzed genotypes displayed a similar pattern of changes in terms of ASC content, i.e. a decrease in leaf ASC concentration at the initial phase of the culture period, until the minimum on day 8 . Subsequently, ASC concentrations in leaves of the control plants gradually increased (Fig. $4 \mathrm{a}-\mathrm{c}$ ).

In $B$. vulgaris ssp. maritima leaves, the highest levels of endogenous ASC were detected on days 16 and 24 of the treatment under strong salt stress conditions. Moderate stress was much less efficient in enhancing endogenous ASC levels in this genotype (Fig. 4a). Similar to B. vulgaris ssp. maritima, leaves of the cultivar Janosik accumulated the highest ASC levels when plants were subjected to severe salt stress (Fig. 4c). In the cultivar Huzar, both strong and moderate stress affected ASC concentrations in a similar manner. A clear, stimulatory effect of salinity on ASC concentration was detected at all sampling points. However, on day 4 of the salt treatment, the increase in ASC levels in plants subjected to severe salinity was not significantly different in comparison to the controls (Fig. 4b).

Throughout the culture period, the endogenous $\mathrm{H}_{2} \mathrm{O}_{2}$ content significantly varied between sampling points in leaves of the control plants. Irrespective of the changing $\mathrm{H}_{2} \mathrm{O}_{2}$ concentrations in leaves of unstressed plants, long-term treatment with salinity significantly increased $\mathrm{H}_{2} \mathrm{O}_{2}$ levels in leaves when compared to the control (Fig. 5a-c). Both B. vulgaris ssp. maritima and the cultivars Huzar and Janosik were characterized by enhanced leaf $\mathrm{H}_{2} \mathrm{O}_{2}$ levels when exposed to salinity. In both sugar beet cultivars, an increase in $\mathrm{H}_{2} \mathrm{O}_{2}$ levels in salt-stressed plants were observed throughout the treatment period (Fig. 5b, c), whereas strongly increased
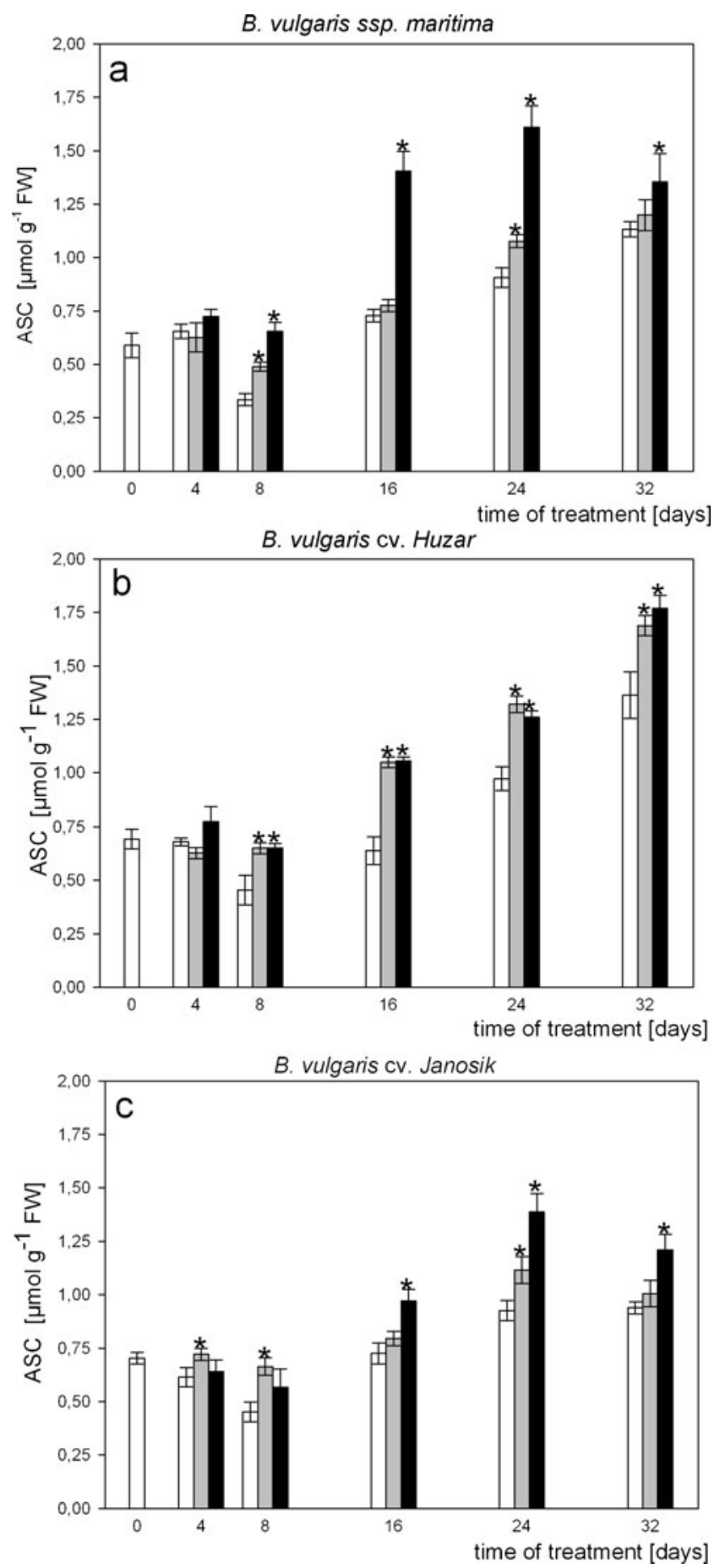

Fig. 4 The level of ascorbic acid (ASC) in leaves of B. vulgaris ssp. maritima (a), B. vulgaris cv. Huzar (b) and B. vulgaris cv. Janosik (c) subjected to long-term salt stress. ASC concentration was measured in leaves of unstressed (control) plants (white bars), plants treated with moderate $(150 \mathrm{mM} \mathrm{NaCl})$ salt stress (gray bars) or strong $(300 \mathrm{mM}$ $\mathrm{NaCl})$ salt stress (black bars). Asterisk denotes significant differences from control with $p<0.05$

$\mathrm{H}_{2} \mathrm{O}_{2}$ levels in leaves of salt-stressed plants of $B$. vulgaris ssp. maritima were detected after 16, 24 and 32 days of the treatment with moderate or strong salinity. However, leaves of 

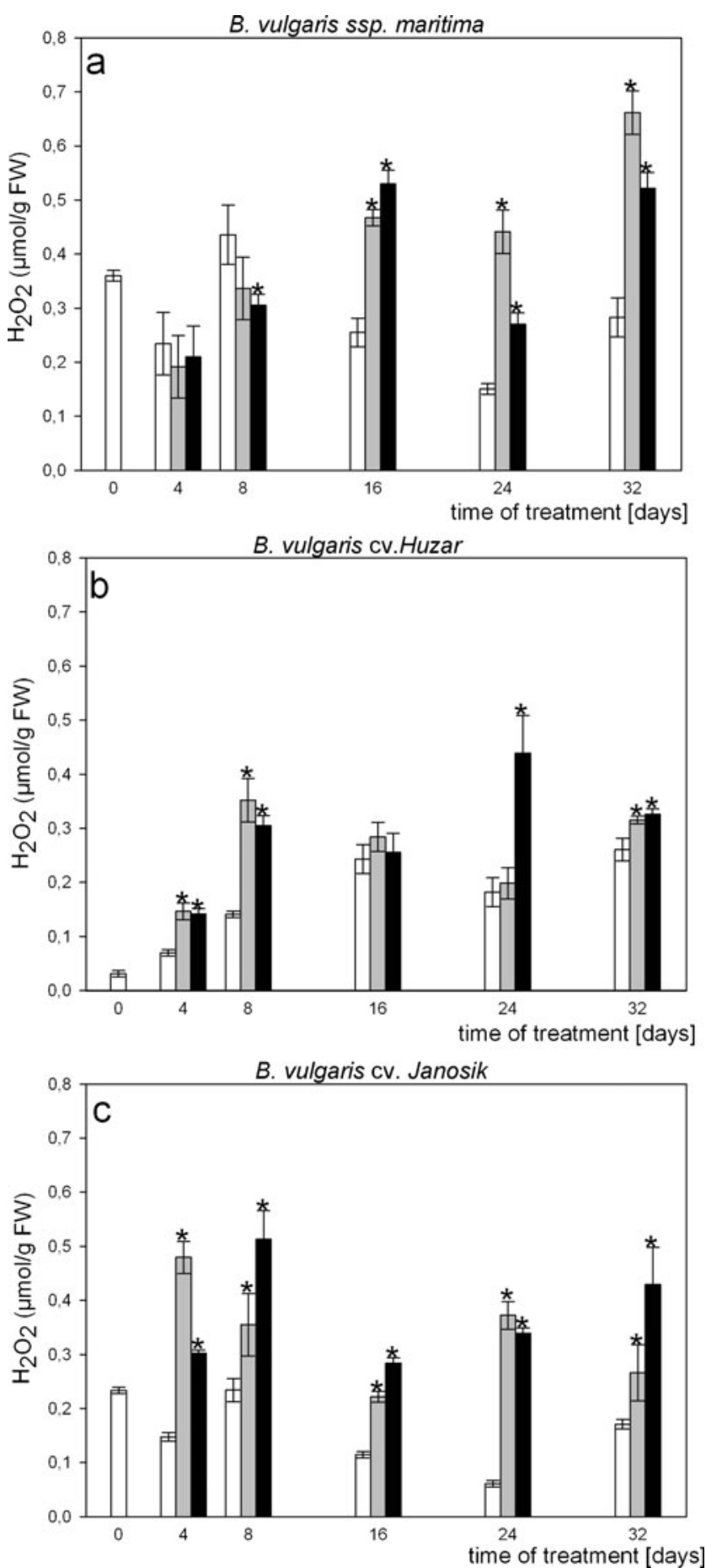

Fig. 5 The level of $\mathrm{H}_{2} \mathrm{O}_{2}$ in leaves of $B$. vulgaris ssp. maritima (a), $B$. vulgaris cv. Huzar (b) and B. vulgaris cv. Janosik (c) subjected to longterm salt stress. $\mathrm{H}_{2} \mathrm{O}_{2}$ concentration was measured in leaves of unstressed (control) plants (white bars), plants treated with moderate $(150 \mathrm{mM}$ $\mathrm{NaCl}$ ) salt stress (gray bars) or strong $(300 \mathrm{mM} \mathrm{NaCl})$ salt stress (black bars). Asterisk denotes significant differences from control with $p<0.05$

stressed plants collected on days 4 or 8 of treatment displayed unchanged (4 days) or even reduced ( 8 days) $\mathrm{H}_{2} \mathrm{O}_{2}$ concentrations when compared to the controls (Fig. 5a).
APX activity in beet leaves increased when plants were subjected to long-term treatment with salt stress, when compared to the control. In the case of B. vulgaris ssp. maritima and Huzar, stimulatory effects of salinity on APX activity were detected throughout the treatment period (Fig. 6a, b), whereas the measurements of APX activity in leaves of the cultivar Janosik revealed the stimulatory effects of salinity on enzyme activity at sampling points ranging from days 16 to 32 of treatment, while the measurements performed on days 4 or 8 of treatment did not reveal any increased APX activity when compared to the control (Fig. 6c). Stimulatory effects of salinity on APX activity were superimposed on salt-independent patterns of changes in enzyme activity revealed in control plants. During the 32-day-long sampling period, APX activities initially increased, reaching maximal values on days 16 (Huzar and Janosik) or 24 (B. vulgaris ssp. maritima) of culture. Then, a period of decline in APX activity was observed resulting in a reduction in the activity levels until the end of the examined period (Fig. 6a-c).

The patterns of changes in $\mathrm{LOOH}$ content during salt treatment varied between the genotypes. In the cultivar Huzar, LOOH content measured after 4, 8, and 16 days of treatment significantly increased due to salinity. The second half of the culture period was characterized by a decrease in LOOH content in the leaves irrespective of salt concentrations in the nutrient medium (Fig. S4b), whereas in the cultivar Janosik increased levels of $\mathrm{LOOH}$ in the leaves of salt-treated plants were detected at all sampling points throughout the treatment period; except on day 4 of treatment, when $\mathrm{LOOH}$ levels were reduced in salt-treated plants (Fig. S4c). In B. vulgaris ssp. maritima, $\mathrm{LOOH}$ content in the leaves of salt-treated plants was not significantly increased when measured after 4 or 8 days of treatment. However, increased LOOH levels were detected on days 16,24 , and 32 of culture of $B$. vulgaris ssp. maritima in the presence of $\mathrm{NaCl}$ concentrations (Fig. S4a).

Detached leaves subjected to short-term treatment with high salinity $(300 \mathrm{mM} \mathrm{NaCl})$ responded with a significant increase in endogenous ASC content. ASC concentrations strongly increased immediately after the imposition of strong salt stress, reaching their maximum at $6 \mathrm{~h}$ of incubation. During the following hours, ASC content slightly decreased and remained relatively stable during the rest of the incubation period (Fig. S5a). The patterns of changes in ASC concentrations in control leaves and those incubated in the presence of $150 \mathrm{mM} \mathrm{NaCl}$ were marked with a decrease detected $10 \mathrm{~h}$ after the beginning of the experiment. Then, ASC levels increased at $12 \mathrm{~h}$ of incubation (Fig. S5a). In contrast to leaves treated with strong salt stress, those cultured in the medium supplemented with moderate salt concentrations did not differ in ASC concentrations from the controls throughout the majority of the treatment period (Fig. S5a).

Endogenous $\mathrm{H}_{2} \mathrm{O}_{2}$ levels in the leaves incubated under short-term salt treatment conditions displayed complex 
patterns of changes. The untreated control was characterized by a slow decrease in $\mathrm{H}_{2} \mathrm{O}_{2}$ levels during the first half of the culture period. Thereafter, a marked increase in $\mathrm{H}_{2} \mathrm{O}_{2}$ concentrations was detected at $10 \mathrm{~h}$ of the culture period, followed by
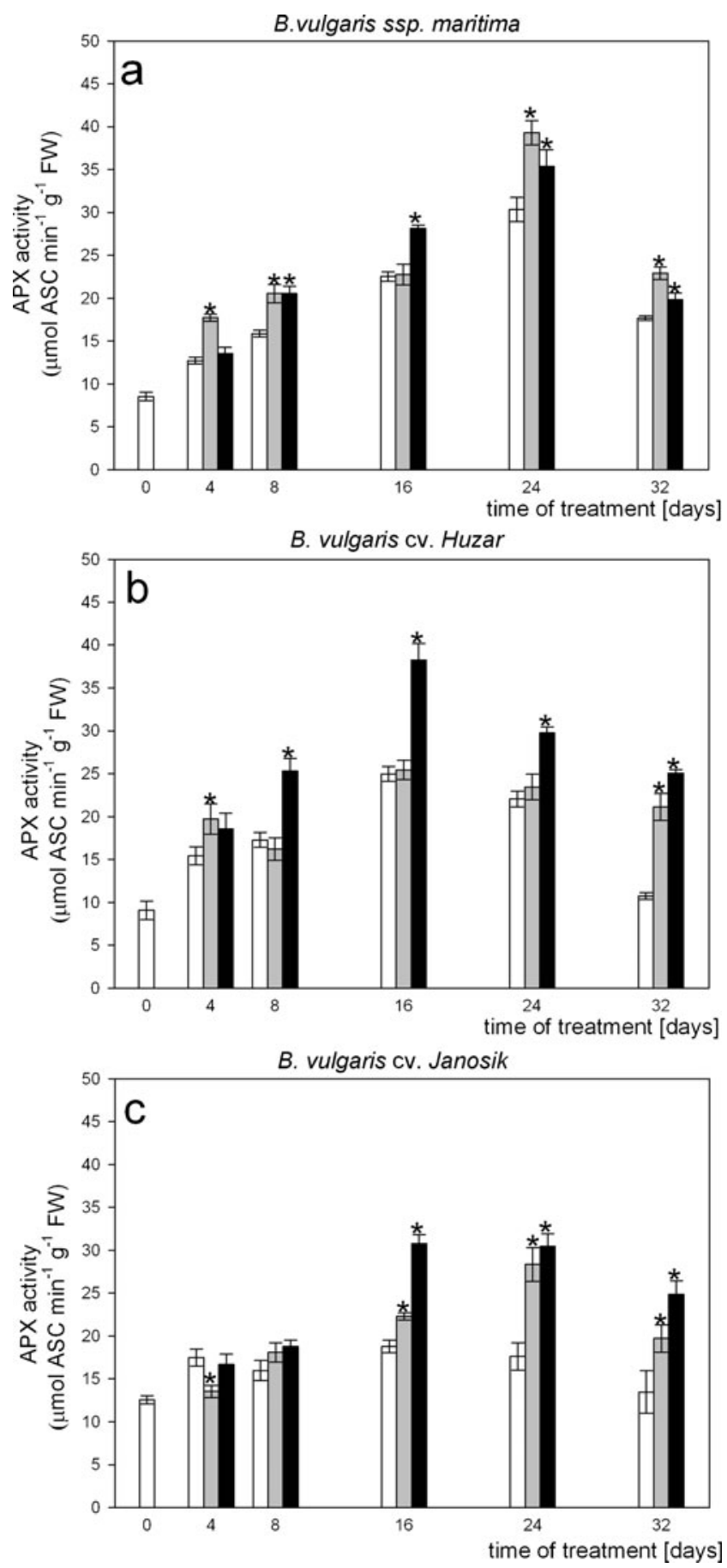

Fig. 6 Ascorbate peroxidase (APX) activity in leaves of $B$. vulgaris ssp. maritima (a), B. vulgaris cv. Huzar (b), and B. vulgaris cv. Janosik (c) subjected to long-term salt stress. APX activity was measured in leaves of unstressed (control) plants (white bars), plants treated with moderate $(150 \mathrm{mM} \mathrm{NaCl})$ salt stress (gray bars) or strong $(300 \mathrm{mM} \mathrm{NaCl})$ salt stress (black bars). Asterisk denotes significant differences from control with $p<0.05$ a sharp reduction in its content during the subsequent hours (Fig. S5b). In contrast to the control leaves, $\mathrm{H}_{2} \mathrm{O}_{2}$ concentrations in leaves subjected to either strong or moderate salinity peaked twice during the 18-h culture period. The maxima of $\mathrm{H}_{2} \mathrm{O}_{2}$ concentrations in leaves treated with $300 \mathrm{mM} \mathrm{NaCl}$ or $150 \mathrm{mM} \mathrm{NaCl}$ were detected at 8 and $14 \mathrm{~h}$ or 4 and $16 \mathrm{~h}$, respectively (Fig. S5b). Moreover, strong salt stress provoked higher increases in $\mathrm{H}_{2} \mathrm{O}_{2}$ concentrations, when compared to moderate stress or the untreated control (Fig. S5b). In contrast to ASC and $\mathrm{H}_{2} \mathrm{O}_{2}$ levels, APX activity did not significantly change during the incubation period. Furthermore, APX activity in salt-stressed leaves was not significantly different from the control (Fig. S5c). High increase in the $\mathrm{LOOH}$ concentrations was observed in both the control and saltstressed leaves after the start of incubation with a maximum at $6 \mathrm{~h}$ of culture. The following hours were marked by a decrease in $\mathrm{LOOH}$ levels, irrespective of salt concentrations in the medium (Fig. S5d).

\section{Discussion}

Sugar beets (Beta vulgaris) are classified as salt-tolerant crops. The salt resistance of sugar beet is largely due to efficient osmotic adjustment. Owing to an accumulation of inorganic ions and compatible solutes, such as glycine betaine, proline, and sucrose, beets are able to maintain photosynthesis and stomatal conductance under salt stress conditions (Katerji et al. 1997; Russell et al. 1998; Ghoulam et al. 2002; Hoffmann 2010; Pakniyat and Amnion 2007; Bagatta et al. 2008). However, during the germination period and early seedling growth, beets display relatively high salt sensitivity (Ghoulam and Fares 2001; Mostafavi 2012). Substantial differences in salt tolerance exist between sugar beet varieties (Ghoulam et al. 2002). B. vulgaris ssp. maritima, a wild relative of sugar beet, is characterized by elevated salt stress resistance, and has been reported to have a higher osmotic adjustment capacity compared to cultivated beets (Pakniyat and Amnion 2007; Bagatta et al. 2008).

In spite of the osmoprotective mechanisms, prolonged salinity causes oxidative stress in leaves (Bor et al. 2003) and significantly impairs the growth of beet plants (Ghoulam and Fares 2001). In order to mitigate oxidative damage, beet leaves respond to salinity with an increase in the activities of antioxidant enzymes, such as peroxidase, catalase, superoxide oxidase, and APX (Bor et al. 2003). These findings suggest that antioxidative responses participate towards the adaptation strategy during salinity conditions in beet leaves. Studies on the role of the antioxidant system in salt tolerance in beet are hampered by the lack of data on the sequence, structure, and regulation of genes coding for most of the antioxidant enzymes in this plant. In this study, we have characterized a full-length transcript and genomic sequence of peroxisomal isoform of Beta vulgaris 
ascorbate peroxidase ( $B v \mathrm{pAPX})$. The sequence of $B v \mathrm{pAPX}$ transcript encodes sequence motifs typical for all APX (see "Results"). The deduced amino acid sequence shares approximately $90 \%$ similarity with pAPX from halophytic plants, Mesembryathemum cristallinum and Salicornia brachiata (Fig. S1).

The BvpAPX genomic sequence consists of five exons separated by four introns (Fig. 1). In contrast, $A m$-pAPX from Avicennia marina (Kavitha et al. 2008), and Os APX3 and Os APX4 encoding pAPX in rice (Teixeira et al. 2006) show different genomic organizations, being composed of nine exons and eight introns. Comparison of $B v \mathrm{pAPX}$ structure with that of $A m$-pAPX (Kavitha et al. 2008) reveals that exons 1,3, 4, and 5 in BvpAPX correspond to exons 1, 7, 8, and 9 of $A m$-pAPX, respectively. However, the sequence of exon 2 in $B v \mathrm{pAPX}$ corresponds to exons 2-6 in Am-pAPX (Fig. 1; Kavitha et al. 2008). Similar to the Am-pAPX gene (Kavitha et al. 2008), BvpAPX lacks an intron in 3'UTR (Fig. 1).

Putative cis-acting elements were identified in the 5' upstream region of $B v \mathrm{pAPX}$ during in silico analysis. Several regulatory elements conferring stress responsiveness, such as ABA-responsive element (ABRE), MYB-binding motif or ethylene-responsive element (ERE) were predicted within a $B v$ pAPX promoter (Table S2). Since a number of potential regulatory sequences may be identified in any nucleotide sequence using bioinformatics tools, detailed analyses will be required to confirm the functionality of the cis-acting elements predicted in the $B v \mathrm{pAPX}$ promoter.

In order to investigate $B v \mathrm{pAPX}$ responsiveness to salt stress, its expression level was measured in plants cultured under conditions of long-term or short-term treatment with salinity. We observed that, under conditions of long-term salt treatment, $B v \mathrm{pAPX}$ expression was up-regulated in leaves due to high salt concentrations (Fig. 4). In contrast, the expression of the pAPX gene in the roots of rice (Hong et al. 2007) and leaves and roots of Lotus japonicus (Rubio et al. 2009) was not affected by salt treatment. However, salinity up-regulated the expression of the cAPX-encoding gene OsAPx 8 in rice (Hong et al. 2007). Expression of APX isoforms, including pAPX, was also enhanced by salinity in sweet potato roots, stems, and leaves (Lin and $\mathrm{Pu}$ 2010). An increase in $B v \mathrm{pAPX}$ expression in leaves of salt-stressed plants was a common feature of both B. vulgaris ssp. maritima and beets representing cultivated varieties (Fig. 3). However, in B. vulgaris ssp. maritima, the salt-dependent stimulation of $B v \mathrm{pAPX}$ transcriptional activity occurred after longer period of salt treatment, than in cultivated beets (Fig. 3). This finding suggests that the activation of certain antioxidant responses, including $B v \mathrm{pAPX}$ expression, may be delayed in leaves of long-term salt-stressed B. vulgaris ssp. maritima plants compared to other beet cultivars.

Similar to BvpAPX expression, APX activity increased in leaves of beet plants cultured under conditions of long-term salt treatment (Fig. 4). Similar to our results, a stimulatory effect of prolonged treatment with high salt concentrations on APX activity in the leaves has been reported for $B$. vulgaris ssp. maritima and sugar beet (Bor et al. 2003), and mangrove, Bruguiera parviflora (Parida et al. 2004).

In both cultivated varieties, transcriptional response of $B v$ pAPX was significantly correlated with APX activity (Figs. 3, 6). In contrast, in B. vulgaris ssp. maritima, a saltdependent enhancement in APX activity was detectable much earlier (on day 4 of treatment) (Fig. 6) than the increase in $B v \mathrm{pAPX}$ transcript level (on day 32 of treatment) (Fig. 3). This finding suggests that other members of the APX family respond to salinity in B. vulgaris ssp. maritima leaves before $B v \mathrm{pAPX}$. Teixeira et al. (2006) reported that genes encoding APX izoenzymes might respond to salt stress with specific expression patterns for each member of the APX family, which suggests functional diversity between APX isoenzymes.

In contrast to the long-term treatment, $B v \mathrm{pAPX}$ expression and APX activity remained largely unaffected in beet leaves subjected to the short-term salt treatment (Fig. S3, S5c). However, the expression level of pAPX in leaves of Avicennia marina transiently increased after $12 \mathrm{~h}$ of exposure to high salinity (Kavitha et al. 2008).

According to the "two phase growth response to salinity" developed by Munns (2005), the initial effect of exposure to salinity is due to osmotic changes outside the salt-treated cells which result in a reduction in the ability of the plant to absorb water. The second phase is due to salt accumulation in leaves, leading to salt toxicity in the plants. The first phase of growth reduction occurred quickly (minutes or hours) after exposure to salinity and is followed by a process of gradual recovery due to the induction of adaptive mechanisms. The second phase is a much slower process taking days, weeks, or months (Munns 2005). Based on the finding that APX activity and $B v \mathrm{pAPX}$ expression were enhanced by salinity under conditions of long-term treatment, while being unaffected by shortterm treatment, the possibility arises that ascorbate peroxidase in beet leaves is involved in responses to $\mathrm{Na}^{+}$toxicity rather than in the protection against the consequences of initial osmotic stress. Although this idea requires further study, it has been demonstrated that accumulation of $O s$ APX 8 transcripts in rice roots exposed to $\mathrm{NaCl}$ was due to the response to ion toxicity and not to an osmotic component of salt stress (Hong et al. 2007).

Leaf ASC content was stimulated by salinity under both long-term and short-term salt treatments (Figs. 4, S5a). Increases in ASC concentrations in response to salt treatment may be explained by the necessity of mitigating the oxidative stress resulting from a simultaneous rise in the concentrations of oxidant agents, such as $\mathrm{H}_{2} \mathrm{O}_{2}$ and $\mathrm{LOOH}$ (Figs. 5, S4). Similar to our results, Bor et al. (2003) reported increased levels of lipid peroxidation in leaves of B. vulgaris ssp. maritima and sugar beet treated with moderate or strong 
salinity. Concentrations of $\mathrm{H}_{2} \mathrm{O}_{2}$ significantly increased in the salt-treated leaves of Bruguiera parviflora. On the other hand, the concentrations of malondialdehyde, a product of lipid peroxidation, remained unchanged in this plant, and the ASC content even decreased in leaves treated with different concentrations of $\mathrm{NaCl}$ (Parida et al. 2004).

Short-term salt treatment was preceded by leaf detachment, which might trigger oxidative stress related to wounding. Both $\mathrm{H}_{2} \mathrm{O}_{2}$ and $\mathrm{LOOH}$ were reported to increase in the plant tissues subjected to mechanical stress (Fabbri et al. 2000; OrozcoCardenas et al. 2001; Soares et al. 2011). In the present study, LOOH levels in leaves subjected to short-term salt treatment increased sharply during the initial hours after the onset of incubation (Fig. S5d). Since the changes in $\mathrm{LOOH}$ concentrations in short-term salt-treated leaves did not seem to be directly related to salt concentrations, $\mathrm{LOOH}$ accumulation in detached leaves may possibly be due to stress linked to wounding. $\mathrm{H}_{2} \mathrm{O}_{2}$ concentrations transiently increased in control leaves, up to the maximum level at $10 \mathrm{~h}$ of incubation (Fig. S5b). Simultaneously, ASC concentration sharply decreased (Fig. S5a). The following hours were marked with an increase in ASC levels with a concomitant decrease in $\mathrm{H}_{2} \mathrm{O}_{2}$ concentrations (Fig. S5a, b). These observations suggest a regulatory interaction between ASC and $\mathrm{H}_{2} \mathrm{O}_{2}$ in detached leaves. Salinity altered $\mathrm{H}_{2} \mathrm{O}_{2}$ levels in detached leaves remarkably, affecting both the timing and the amplitude of changes in $\mathrm{H}_{2} \mathrm{O}_{2}$ concentrations (Fig. S5b). In contrast, salinity did not increase $\mathrm{H}_{2} \mathrm{O}_{2}$ concentrations in detached leaves of rice. $\mathrm{H}_{2} \mathrm{O}_{2}$ in salt-treated rice leaves remained at low levels due to increased activities of $\mathrm{H}_{2} \mathrm{O}_{2}$-scavenging enzymes, such as guaiacol peroxidase and APX (Lin and Kao 2000).

Besides the changes related to salt administration, the parameters studied varied in a salt-independent manner in the course of the long-term culture (see controls in Figs. 3, $4,5,6$, Fig. S4). The variation in the control may result from a correlation between redox metabolism, leaf photosynthesis, and developmental processes. It was shown that juvenile beet leaves complete their ontogenetic cycle, composed of the phase of leaf area expansion followed by the photosynthetic maturity, within about 30 days after appearance. Within this time frame, the photosynthetic capacity $\left(P_{c}\right)$ displays a dynamic pattern of changes, with an initial increase with the leaf area expansion up to the photosynthetic maturity, at which $P_{c}$ was maximal, followed by a decline with the onset of leaf senescing (Hodanova 1981). Since redox agents and antioxidant enzymes are strongly associated with photosynthesis (Karpinski et al. 1997; Yabuta et al. 2007), they are expected to respond to alterations in photosynthesis rate. Moreover, ASC, $\mathrm{H}_{2} \mathrm{O}_{2}$, and related enzymes participate in leaf development and leaf area expansion, being involved in cell growth, cell wall stiffening, lignification, and tracheary vessel development (Rodriguez et al. 2002; Green and Fry 2005; Cheeseman 2009). Consequently, the endogenous levels and distribution patterns of redox metabolites change during leaf ontogeny (Niewiadomska et al. 2009). Therefore, the first leaf of a young sugar beet plant should be considered a dynamic system in terms of development and photosynthetic activity. Consequently, the changes in redox metabolism in beet leaves, induced by salinity, seem to be superimposed on alterations related to photosynthesis and development.

In conclusion, we isolated and characterized a $B v \mathrm{pAPX}$ gene encoding a peroxisomal isoform of ascorbate peroxidase in Beta vulgaris. BvpAPX is transcriptionally up-regulated upon prolonged salt stress in leaves of both wild and cultivated beets. However, a longer exposure to salinity was required to stimulate $B v \mathrm{pAPX}$ expression in salt tolerant $B$. vulgaris ssp. maritima when compared with sugar beet varieties. Putatively, the efficient osmoprotection reported for $B$. vulgaris ssp. maritima (Bagatta et al. 2008) is able to restrict $\mathrm{Na}^{+}$toxicity in leaves for longer periods than that in saltsensitive varieties. It is possible that assessment of the timing of transcriptional activation of the BvpAPX gene in plants challenged with long-term treatments with salinity may provide cues for screening beet genotypes for salt tolerance.

Acknowledgments This study was financially supported by a grant from the National Science Centre, Poland (Grant No. 3005/B/P01/2010/39).

Open Access This article is distributed under the terms of the Creative Commons Attribution License which permits any use, distribution, and reproduction in any medium, provided the original author(s) and the source are credited.

\section{References}

Abe H, Urao T, Ito T, Seki M, Shinozaki K, Yamaguchi-Shinozaki K (2003) Arabidopsis AtMYC2 (bHLH) and AtMYB2 (MYB) function as transcriptional activators in abscisic acid signaling. Plant Cell 15:63-78

Ashraf M (2009) Biotechnological approach of improving plant salt tolerance using antioxidants as markers. Biotech Adv 27:84 93

Bagatta M, Pacifico D, Mandolino G (2008) Evaluation of the osmotic adjustment response within the genus Beta. J Sugar Beet Res 45:119-133

Bao X, Franks RG, Levin JZ, Liu Z (2004) Repression of AGAMOUS by BELLRINGER in floral and inflorescence meristems. Plant Cell 16:1478-1489

Bhattacharjee S (2005) Reactive oxygen species and oxidative burst: Roles in stress, senescence and signal transduction in plants. Curr Sci 89:1113-1121

Bor M, Ozdemir F, Turkan I (2003) The effects of salt stress on lipid peroxidation and antioxidants in leaves of sugar beet Beta vulgaris L. and wild beet Beta maritima L. Plant Sci 164:77-84

Bunkelmann JR, Trelease RN (1996) Ascorbate peroxidase - a prominent membrane protein in oilseed glyoxysomes. Plant Physiol 110:589-598

Chang WC, Lee TY, Huang HD, Huang HY, Pan RL (2008) PlantPAN: Plant promoter analysis navigator, for identifying combinatorial cis- 
regulatory elements with distance constraint in plant gene groups. BMC Genomics 9:561

Cheeseman JM (2009) Seasonal patterns of leaf $\mathrm{H}_{2} \mathrm{O}_{2}$ content: reflections of leaf phenology, or environmental stress? Funct Plant Biol 2009(36):721-731

Chen C, Chen Z (2000) Isolation and characterization of two pathogenand salicylic acid-induced genes encoding WRKY DNA-binding proteins from tobacco. Plant Mol Biol 42:387-396

Claros MG, von Heijne G (1994) TopPred II: an improved software for membrane protein structure predictions. CABIOS 10:685-686

Dąbrowska G, Kata A, Goc A, Szechyńska-Hebda M, Skrzypek E (2007) Characteristics of the plant ascorbate peroxidase family. Acta Biol Cracow Ser Bot 49:7-17

Davletova S, Rizhsky L, Liang H, Shengquiang Z, Oliver DJ, Coutu J, Shulayev V, Schlauch K, Mittler R (2005) Cytosolic ascorbate peroxidase 1 is a central component of the reactive oxygen gene network of Arabidopsis. Plant Cell 17:268-281

Del Rio L, Corpas FJ, Sandalio LM, Palma JM, Gomez M, Barroso JB (2002) Reactive oxygen species, antioxidant systems and nitric oxide in peroxisomes. J Exp Bot 53:1255-1272

Del Rio L, Pastori GM, Palma JM, Sandalio LM, Sevilla F, Corpas FJ, Jimenez A, Lopez-Huertas E, Hernandez JA (1998) The activated oxygen role of peroxisomes in senescence. Plant Physiol 116:11951200

DeLong JM, Prange RK, Hodges DM, Forney CF, Bishop MC, Quilliam M (2002) Using a modified ferrous oxidation-xylenol orange (FOX) assay for detection of lipid hydroperoxides in plant tissue. J Agric Food Chem 50:248-254

Fabbri AA, Fanelli C, Reverberi M, Ricelli A, Camera E, Urbanelli S, Rossini A, Picardo M, Altamura MM (2000) Early physiological and cytological events induced by wounding in potato tuber. J Exp Bot 51:1267-1275

Foyer CH, Noctor G (2005) Oxidant and antioxidant signalling in plants: a re-evaluation of the concept of oxidative stress in a physiological context. Plant Cell Environ 28:1056-1071

Ghoulam C, Fares K (2001) Effect of salinity on seed germination and early seedling growth of sugar beet (Beta vulgaris L.). Seed Sci Technol 29:357-364

Ghoulam C, Foursy A, Fares K (2002) Effects of salt stress on growth, inorganic ions and proline accumulation in relation to osmotic adjustment in five sugar beet cultivars. Environ Exp Bot 47:39 50

Green MA, Fry SC (2005) Vitamin C degradation in plants via enzymatic hydrolysis of 4-O-oxalyl-L-threonate. Nature 433:83-88

Higo K, Ugawa Y, Iwamoto M, Korenaga T (1999) Plant cis-acting regulatory DNA elements (PLACE) database. Nucleic Acids Res 27:297-300

Hodanova D (1981) Photosynthetic capacity, irradiance and sequential senescence of sugar beet leaves. Biol Plant 23:58-67

Hoffmann CM (2010) Sucrose accumulation in sugar beet under drought stress. J Agron Crop Sci 196:243-252

Hong CY, Hsu YT, Tsai YC, Kao CH (2007) Expression of ASCORBATE PEROXIDASE 8 in roots of rice (Oryza sativa L.) seedlings in response to $\mathrm{NaCl}$. J Exp Bot 58:3273-3283

Ishikawa T, Shigeoka S (2008) Recent advances in ascorbate biosynthesis and the physiological significance of ascorbate peroxidase in photosynthesizing organisms. Biosci Biotechnol Biochem 72:1143-1154

Jespersen HM, Kjaersgård IVH, Østergaard L, Welinder KG (1997) From sequence analysis of three novel ascorbate peroxidases from Arabidopsis thaliana to structure, function and evolution of seven types of ascorbate peroxidase. Biochem J 326:305-310

Kaplan B, Davydov O, Knight H, Galon Y, Knight MR, Fluhr R, Fromm $\mathrm{H}$ (2006) Rapid transcriptome changes induced by cytosolic $\mathrm{Ca}^{2+}$ transients reveal ABRE-related sequences as $\mathrm{Ca}^{2+}$-responsive cis elements in Arabidopsis. Plant Cell 18:2733-2748
Kapustin Y, Souvorov A, Tatusova T, Lipman D (2008) Splign: algorithms for computing spliced alignments with identification of paralogs. Biol Direct 3:20

Karpinski S, Escobar C, Karpinska B, Creissen G, Mullineaux P (1997) Photosynthetic electron transport regulates the expression of cytosolic ascorbate peroxidase genes in Arabidopsis during excess light stress. Plant Cell 9:627-640

Katerji N, van Hoorn JW, Hamdy A, Mastrorilli M, Mou Karzel E (1997) Osmotic adjustment of sugar beets in response to soil salinity and its influence on stomata, conductance, growth and field. Agric Water Manag 34:57-69

Kavitha K, Venkatamaran G, Parida A (2008) An oxidative and salinity stress induced peroxisomal ascorbate peroxidase from Avicennia marina: molecular and functional characterization. Plant Physiol Biochem 46:794-804

Lescot M, Déhais P, Moreau Y, De Moor B, Rouzé P, Rombauts S (2002) PlantCARE: a database of plant cis-acting regulatory elements and a portal to tools for in silico analysis of promoter sequences. Nucleic Acids Res 30:325-327

Lin CC, $\mathrm{Kao} \mathrm{CH}$ (2000) Effect of $\mathrm{NaCl}$ stress on $\mathrm{H}_{2} \mathrm{O}_{2}$ metabolism in rice leaves. Plant Growth Regul 30:151-155

Lin KH, Pu SF (2010) Tissue- and genotype-specific ascorbate peroxidase expression in sweet potato in response to salt stress. Bol Plant 54:664-670

Matys V, Fricke E, Geffers R, Gößling E, Haubrock M, Hehl R, Hornischer K, Kel AE, Kel-Margoulis OV, Kloos DU, Land S, Lewicki-Potapov B, Michael H, Münch R, Reuter I, Rotert S, Saxel H, Scheer M, Thiele S, Wingender E (2003) TRANSFAC: transcriptional regulation, from patterns to profiles. Nucleic Acids Res 31:374-378

Molina C, Grotewold E (2005) Genome wide analysis of Arabidopsis core promoters. BMC Genomics 6:25

Mostafavi K (2012) Effect of salt stress on germination and early seedling growth stage of sugar beet cultivars. American-Eurasian J Sust Agric 6:120-125

Mullen RT, Trelease RN (2000) The sorting signals for peroxisomal membrane-bound ascorbate peroxidase are within its C-terminal tail. J Biol Chem 275:16337-16344

Munns R (2005) Genes and salt tolerance: bringing them together. New Phytol 167:645-663

Niewiadomska E, Polzien L, Desel C, Rozpadek P, Miszalski Z, Krupinska K (2009) Spatial patterns of senescence and development-dependent distribution of reactive oxygen species in tobacco (Nicotiana tabacum ) leaves. J Plant Physiol 166:1057-1068

Orozco-Cárdenas ML, Narváez-Vásquez J, Ryan CA (2001) Hydrogen peroxide acts as a second messenger for the induction of defense genes in tomato plants in response to wounding, systemin, and methyl jasmonate. Plant Cell 13:179-191

Pakniyat H, Amnion M (2007) Sodium and proline accumulation as osmoregulators in tolerance of sugar beet genotypes to salinity. Pak J Biol Sci 22:4081-4086

Parida AK, Das AB, Mohanty P (2004) Investigations on the antioxidative defence responses to $\mathrm{NaCl}$ stress in a mangrove, Bruguiera parviflora: Differential regulations of isoforms of some antioxidative enzymes. Plant Growth Regul 42:213-226

Rawat R, Xu ZF, Yao KM, Chye ML (2005) Identification of ciselements for ethylene and circadian regulation of the Solanum melongena gene encoding cysteine proteinase. Plant Mol Biol 57:629-643

Rodríguez AA, Grunberg KA, Taleisnik EL (2002) Reactive oxygen species in the elongation zone of maize leaves are necessary for leaf extension. Plant Physiol 129:1627-1632

Rubio MC, Bustos-Sanmamed P, Clemente MR, Becana M (2009) Effects of salt stress on the expression of antioxidant genes and proteins in the model legume Lotus japonicus. New Phytol 181:851-859 
Russell BL, Rathinasabapathi B, Hanson AD (1998) Osmotic stress induces expression of choline monooxygenase in sugar beet and amaranth. Plant Physiol 116:859-865

Shao HB, Chu LY, Shao MA, Jaleel CA, Mi HM (2008) Higher plant antioxidants and redox signalling under environmental stresses. Compt Rend Biol 331:433-441

Smethurst CF, Gill WM, Shabala S (2009) Using excised leaves to screen lucerne for salt tolerance. Physiological and cytological evidence. Plant Sign Behav 4:39-41

Soares NC, Wojtkowska J, Jackson PA (2011) A proteomic analysis of the wound response in Medicago leaves reveals the early activation of a ROS-sensitive signal pathway. J Proteomics 74:14111420

Tamura K, Peterson D, Peterson N, Stecher G, Nei M, Kumar S (2011) MEGA5: molecular evolutionary genetics analysis using maximum likelihood, evolutionary distance, and maximum parsimony methods. Mol Biol Evol 28:2731-2739

Teixeira FK, Menezes-Benavente L, Galvão VC, Margis R, MargisPinheiro M (2006) Rice ascorbate peroxidase gene family encodes functionally diverse isoforms localized in different subcellular compartments. Planta 224:300-314

Tyburski J, Dunajska K, Mazurek P, Piotrowska P, Tretyn A (2009) Exogenous auxin regulates $\mathrm{H}_{2} \mathrm{O}_{2}$ metabolism in roots of tomato (Lycopersicon esculentum Mill.) seedlings affecting the expression and activity of $\mathrm{CuZn}$-superoxide dismutase, catalase, and peroxidase. Acta Physiol Plant 31:249-260

Veljovic-Jovanovic S, Noctor G, Foyer CH (2002) Are leaf hydrogen peroxide concentrations commonly overestimated? The potential influence of artefactual interference by tissue phenolics and ascorbate. Plant Physiol Biochem 40:501-507

Wawrik B, Paul JH, Tabita FR (2002) Real-time PCR quantification of rbcL (ribulose-1,5-bisphosphate carboxylase/oxygenase) mRNA in diatoms and pelagophytes. Appl Environ Microbiol 68:3771-3779

Yabuta Y, Mieda T, Rapolu M, Nakamura A, Motoki T, Maruta T, Yoshimura K, Ishikawa T, Shigeoka S (2007) Light regulation of ascorbate biosynthesis is dependent on the photosynthetic electron transport chain but independent of sugars in Arabidopsis. J Exp Bot 58:2661-2671 